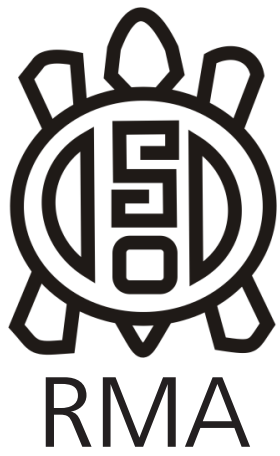

Arqueología

\title{
El registro cerámico inkaico en la Puna de Jujuy (Argentina): una aproximación a partir de colecciones museológicas
}

\author{
The Inka ceramic record in the Puna of Jujuy (Argentina): an approach \\ based on museum collections
}

María Josefina Pérez Pieroni*

*Instituto de Arqueología y Museo, Facultad de Ciencias Naturales e IML, Universidad Nacional de Tucumán. Instituto Superior de Estudios Sociales. CONICET.

E-mail: josefinaperezp@gmail.com

\begin{abstract}
Resumen
Con el objetivo de aportar al entendimiento de la influencia estatal en la producción de materiales cerámicos en la Puna de Jujuy (Argentina), se aborda un conjunto de 43 recipientes considerados de cronología e influencia inka en base a sus morfologías y motivos de diseño. Proceden de diferentes sitios arqueológicos de la región, principalmente de contextos funerarios, y se encuentran depositados en colecciones museológicas. Sobre los mismos se realizaron observaciones macroscópicas de atributos vinculados a la cadena operativa de producción y se propone una clasificación morfológica a partir de otras publicadas previamente por distintos autores. Los resultados nos permiten postular una producción de formas de influencia inka dentro de tradiciones tecnológicas locales previas de momentos prehispánicos tardíos, en particular aquella relacionada a la cerámica del estilo Yavichicha. Los elementos incorporados fueron principalmente morfologías que se encuentran a lo largo de todo el imperio y que probablemente operaron como indices de la presencia imperial en la trama de las diferentes relaciones de negociación desplegadas por los inkas.
\end{abstract}

Palabras clave: Cerámica; Inka; Puna de Jujuy; Tradiciones tecnológicas; Colecciones museológicas.

\begin{abstract}
In order to provide greater insights into the understanding of state influence on ceramic production in the Puna of Jujuy (Argentina), we analyze/study a set of 43 vessels considered of Inka influence and chronology according to their morphologies and design motifs. These vessels come from different archaeological sites in the region, mainly from funerary contexts, and are deposited in museum collections. Different macroscopic attributes were registered, in relation to the operative production chain. In addition, a morphological classification is proposed based on reports/ findings from other authors. The results allow us to suggest a production of Inka-influenced forms/designs within local technological traditions of late pre-Hispanic times, particularly those linked to the Yavi-chicha ceramic style. The elements incorporated mainly comprise morphologies/forms found across the empire and that probably served as indexes of the imperial presence in the different negotiation relationships developed by the Inkas.
\end{abstract}

Keywords: Pottery; Inka; Puna of Jujuy; Technological traditions; Museum collections.

\section{Introducción}

La expansión del imperio Inka al Noroeste Argentino y sus consecuencias materiales han despertado gran interés en la arqueología de esta región. La Puna de la Provincia de Jujuy (Argentina) ha recibido parte de esta atención, aunque principalmente enfocada en la detección de sitios vinculados a la presencia imperial, sus características arquitectónicas, el impacto sobre aspectos productivos, como la agricultura, las vías de circulación, entre otros (Albeck et al., 2007; Krapovickas, 1983; Raffino et al., 1986; Ruiz, 1996). Sin embargo, la influencia que tuvo la incorporación de esta área al imperio sobre la manufactura de diferentes tipos de materialidades $y$, en particular, en la cerámica, no ha recibido tanto interés. Son una excepción los trabajos realizados por Cremonte y su equipo, quienes analizan aspectos tecnológicos de ciertos estilos cerámicos de momentos Inka, como el Yavichicha (Cremonte, 2014) y el Inka Pacajes (Cremonte et al., 2015); y el análisis de formas inkaicas realizado por Zaburlín (2015) en su tesis, también sobre materiales de colección y publicados. A pesar de que en otras zonas del NOA, incluyendo la vecina quebrada de Humahuaca, diferentes autores han señalado la importancia de esta materialidad en la expansión de este imperio, en la conformación de alianzas e intercambios, y la movilización 
de recursos para su producción y circulación (Calderari, 1991; Calderari y Williams, 1991; Cremonte et al., 2010; D’Altroy et al., 1998; González y Tarragó, 2004; Marchegiani, 2012; Otero, 2015; Runcio, 2012; Williams, 2000, 2004; Williams y Cremonte, 1997; entre otros).

Con el objetivo de aportar al entendimiento de la influencia estatal en la producción de materiales cerámicos en esta porción de los Andes, en este trabajo abordamos un conjunto de recipientes que hemos considerado como de cronología e influencia inkaica y que pueden ser clasificados como Inka provincial e Inka mixto (sensu Calderari y Williams, 1991), en base a sus morfologías y motivos de diseño, procedentes de diferentes sitios de la Puna de Jujuy y que se encuentran depositados en colecciones museológicas. Si bien para entender la producción circulación y uso de la cerámica en momentos de expansión del imperio deberíamos también tener en cuenta la cerámica no clasificable como Inka, sin importar su estilo (como señala Williams, 2000), dado que trabajamos con piezas de colecciones sin fechados y sin posibilidad de asociar piezas entre sí porque no tenemos información sobre sus contextos, en esta primera aproximación elegimos circunscribirnos a las piezas que consideramos pueden ser asociadas con cierta seguridad a este rango cronológico, teniendo en cuenta el estado del conocimiento actual. A pesar de estas limitaciones, consideramos que este primer aporte es relevante dada la escasez de trabajos sobre esta temática en el área y porque nos permite realizar una clasificación morfológica y aproximación a la diversidad de materiales de influencia inka en el área a partir del relevamiento de diferentes colecciones museográficas.

Para abordar este objetivo, partimos desde una perspectiva de la teoría de la práctica, que considera que la cerámica se produce en el marco de tradiciones tecnológicas, que son parte de habitus (Bourdieu, 1993) compartidos. Las tradiciones tecnológicas son abordadas a partir del estudio de atributos producto de las operaciones y elecciones tecnológicas dentro de las cadenas operativas (Lemonnier, 1992).

\section{La muestra estudiada y la metodología}

Se consideraron piezas con influencia inka a 43 recipientes procedentes de diferentes colecciones de museo relevadas en los últimos años. Para identificarlos, nos basamos en la clasificación morfológica de Meyers (1975), retomada por Bray (2004), quien define categorías formales en base al relevamiento de una colección de recipientes de Saqsaywaman y las estructura para facilitar la comparación con la alfarería inka de las provincias (Bray, 2004). También hemos tomado en cuenta atributos de recipientes identificados para estos momentos por otros autores para el área y áreas vecinas, tanto de las morfologías como de los motivos pintados que se incorporan en algunos tipos cerámicos en estos momentos (Ávila, 2009; Calderari y Williams, 1991; Nielsen, 1997, 2007; Zaburlín, 2015). Incluimos a su vez una forma abierta, porque no la hemos registrado en los contextos analizados por nosotros y datados en momentos prehispánicos tardíos y porque aparece en un par de piezas exactamente iguales en Moreta, lo cual constituye una característica de recipientes imperiales, tanto cerámicos como en otros materiales (Bray, 2003) ${ }^{1}$.

En total, se relevaron 361 piezas cerámicas depositadas en distintos museos del país y del exterior, de las cuales 162 se encuentran en el Museo Etnográfico Juan B. Ambrosetti (en adelante ME), y corresponden a la Colección Doncellas (en adelante CD), que fuera obtenida por Casanova entre los años 1941-1943². Otras 100 se encuentran en el Museo de Ciencias Naturales de la UNLP en La Plata (en adelante MLP), y corresponden a la colección Márquez Miranda (en adelante CMM) ( $n=66)$, obtenidas por ese investigador del sitio Moreta en 1945; a la Moreno (en adelante CM) $(n=29)$, procedentes de diferentes sitios de la Puna excavados por Gerling ${ }^{3}$ (Río San Juan Mayo, Casabindo, Surugá); y a la Muñiz Barreto (en adelante CMB) $(n=5)$, procedentes del Río San Juan Mayo, obtenidas por Weiser y Schubel entre 1919 y 1920. En el Instituto Interdisciplinario Tilcara (FFyL, UBA) (en adelante IIT) se registraron 64 recipientes, algunos de la Colección Doncellas ( $n=24)$, otros de Queta (en adelante CQ) $(n=37)$ y los restantes de otras localidades de la Puna de Jujuy (3). Todas fueron obtenidas por Casanova en la década de 1940. En el Museo Quai Branly (en adelante MQB) se analizaron 35 piezas obtenidas por Boman (1908) en el marco de la Misión Senechal de la Grange-Crequi Monfort, del Pukará de Rinconada $(n=15)$ y de otros sitios de la puna de Jujuy que visitó.

De estos sitios de donde proceden las muestras y para los que hemos podido identificar recipientes de influencia inkaica, Doncellas ${ }^{4}$ es un semiconglomerado asociado a estructuras de cultivo y a entierros en grutas en los

\footnotetext{
1 Ávila (2009) releva una forma muy similar para el estilo Yavi, que denomina escudillas asimétricas, entre los recipientes de este estilo en la Quebrada de Humahuaca y la ubica en un componente de Desarrollos Regionales Temprano o PDR I. Es una morfología muy semejante a la de las calabazas empleadas como recipiente y que se encuentran en abundancia en la colección Doncellas y otros sitios de la Puna.

2 La colección se conformó en base a las excavaciones en el área de cementerio de Doncellas exclusivamente, por Casanova, quién abrió aproximadamente 200 enterratorios en uno de los farallones que rodean al sitio. Incluye una gran cantidad de objetos en diferentes materiales (Pérez de Micou, 1997). Otros autores han analizado previamente parte o todos los recipientes de esta colección (p. ej. Pérez y Killián Galván, 2011; Uribe y Agüero, 2005; Zaburlín, 2015), como así también otros materiales que integran la colección, que es muy diversa (ver Pérez de Micou, 1997).

3 Gerling visitó la Puna en 1894 y en 1896-1897, enviado por Moreno a recolectar materiales para el Museo de Ciencias Naturales (LehmannNistche, 1904). Los materiales recuperados y la información provista por Gerling son sintetizadas en la publicación de Lehmann-Nistche (1904).

4 También conocido como Agua Caliente, ver Vignati (1938) y Ottonello (1973)
} 
farallones que rodean el sitio, que ha sido trabajado por Vignati (1938), Casanova (1943), Alfaro (1988) y Ottonello (1973), quienes postularon ocupaciones de momentos prehispánicos tardíos y posiblemente reutilizaciones de este sitio en momentos coloniales. Este conglomerado no presenta arquitectura que haya sido asignada a momentos inkaicos (Albeck et al., 2007).

Moreta es mencionado como un pueblo de indios chichas y tambo inkaico por Matienzo en su carta al rey en 1566 (Levillier, 1918; cito en Angiorama et al., 2017). Desde las excavaciones de Márquez Miranda, que no fueron publicadas ni se han hallado notas de campo, fue vuelto a trabajar nuevamente por nuestro equipo en años recientes. Hemos podido registrar un sector con recintos de vivienda con arquitectura chicha y un basurero, un sector defensivo en la cima de una loma contigua, un RPC junto a una serie de terrazas, corrales y una amplia extensión con estructuras de cultivo (Angiorama et al., 2017 , 2018). De acuerdo a los fechados, las ocupaciones habrían abarcado desde mediados del primer milenio y todo el período Tardío, con algunas evidencias de su uso con posterioridad al contacto hispano-indígena (Angiorama et al., 2018, Pérez Pieroni y Angiorama, 2018). Los materiales cerámicos fragmentarios analizados hasta la fecha no incluyen recipientes inkaicos, aunque si hemos hallado fragmentos en recolecciones superficiales, que aún no hemos analizado.

El Pukará de Rinconada es un conglomerado encima de una meseta de ignimbrita que presenta una posición defensiva y un único acceso. Además de Boman (1908), ha sido estudiado por otros investigadores (Alfaro y Suetta, 1970; Ruiz, 1996; Suetta y Alfaro, 1979), que han identificado una ocupación preinkaika y otra inkaica posterior. El trabajo con los materiales de colección obtenidos por Boman también permiten señalar una posible continuidad en el uso en momentos coloniales (Pérez Pieroni, 2018a).

El sitio de Queta es descrito por Alfaro (1983) como un conglomerado sin defensas y por Raffino y colaboradores (1986) como un tambo inka, con la presencia de Rectángulos Perimetrales Compuestos (RPC), corrales y posibles collca. En Casabindo y Surugá, Lehmann-Nistche (1904) menciona que Gerling obtuvo los recipientes relevados de contextos funerarios, pero no se brinda más información sobre sus características ni su ubicación, ni sobre las de Cochinoca. Las denominaciones Casabindo, Cochinoca y San Juan Mayo probablemente refieren a áreas y no a sitios concretos (Zaburlín, 2015).

De acuerdo a la escasa información disponible, las excavaciones realizadas en los sitios mencionados corresponden en su mayoría a contextos funerarios. Son excepciones Moreta, donde desconocemos las áreas excavadas por Márquez Miranda5 ${ }^{5}$ y el Pukará

5 A partir de lo observado en el campo, suponemos que se ha limitado de Rinconada, donde Boman excavó áreas domésticas y entierros en las grutas de las mesadas que rodean este Pukará (Boman, 1908). De acuerdo a los estudios previos citados para estos sitios, los realizados sobre los materiales cerámicos y la escasa información asociada a estas colecciones (Pérez Pieroni, 2018a; Angiorama et al., 2017), no se trataría de sitios inkaicos puros, sino de contextos prehispánicos tardíos donde la presencia imperial se registra en los materiales y/o en la presencia de elementos arquitectónicos.

En la Tabla 1 se muestra la proveniencia de los recipientes relevados y la cantidad de aquellos analizados para este trabajo por sitio o área de procedencia.

El relevamiento realizado consistió en observaciones macroscópicas y con lupa de mano (20X) de atributos morfológicos y otros asociados a la cadena operativa de manufactura que venimos empleando en el trabajo con material cerámico fragmentario y de colecciones y que fueron registradas en planillas diseñadas por nosotros (Pérez Pieroni, 2015, 2018b). Donde estuvieron disponibles, se asentaron las numeraciones e información de fichas y catálogos. Los atributos incluyen la identificación, donde fue posible, de macrotrazas relacionadas con el modelado (siguiendo a García Roselló y Calvo Trías, 2013), la morfología de los recipientes (según el sistema clasificatorio de Balfet et al., 1992), diferentes dimensiones de los mismos y atributos de bordes, bases y asas. Las morfologías analizadas fueron luego comparadas con la clasificación de formas inka de Meyers (1975), empleada también por Bray (2003), quien analiza en mayor detalle estas formas. Por otro lado, se registraron los acabados de superficie, incluyendo la aplicación de color (engobes o pintura), la presencia de motivos pintados y la porción del recipiente donde se localizan. Finalmente, registramos los colores de superficies y núcleos (donde se pudieron observar), como modo de aproximación a la cocción, y el tipo general de inclusiones a nivel macroscópico (con lupa de mano).

\section{Resultados}

A partir de la observación de la Tabla 1 se puede notar que los sitios con mayor proporción de piezas identificadas como de influencia imperial son Surugá y Cochinoca, pero los mismos se encuentran representados por muy pocos ejemplares (dos y tres respectivamente) por lo que no consideramos que se trate de una muestra representativa. Entre aquellos sitios con mayor cantidad de ejemplares, Moreta es el que presenta un porcentaje algo mayor que el resto de los sitios (16,7\%), mientras que el Pukará de Rinconada es el que menor proporción presenta $(6,7 \%)$, a pesar de que se ha planteado una ocupación Inka en el mismo, que involucró importantes remodelaciones

al sector del poblado con arquitectura chicha. Sin embargo, esto no quiere decir que el material provenga de contextos domésticos, dado que sabemos de la existencia de enterratorios bajo los pisos de ocupación (Angiorama et al., 2017). 


\begin{tabular}{|l|l|l|l|}
\hline Sitio & $\mathbf{N}^{\circ}$ piezas relevadas & $\begin{array}{l}\mathbf{N}^{\circ} \text { piezas influencia } \\
\text { inka }\end{array}$ & $\%$ \\
\hline Doncellas & 186 & 22 & 11,8 \\
\hline Moreta & 66 & 11 & 16,7 \\
\hline Casabindo & 20 & 2 & 10 \\
\hline Río San Juan Mayo & 12 & 0 & 0 \\
\hline Surugá & 2 & 1 & 50 \\
\hline Cochinoca & 3 & 1 & 33,3 \\
\hline Queta & 38 & 5 & 13,1 \\
\hline Pukará de Rinconada & 15 & 1 & 6,7 \\
\hline Otros & 19 & 0 & 0 \\
\hline TOTAL & 361 & 44 & 12,2 \\
\hline
\end{tabular}

Tabla 1. Total de recipientes relevados y de recipientes considerados de influencia inka por sitio o área de procedencia.

Table 1. Total number of containers surveyed and of vessels considered to be of Inka influence by site or area of origin. de la arquitectura y hallazgos de diferentes materiales, incluyendo alfarería de formas imperiales (Ruiz, 1996). Sin embargo, debemos tener en cuenta que también en este sitio la cantidad de recipientes representados en la muestra son escasos $(n=15)$. En otros sitios, como Doncellas, Queta y Casabindo vemos que el porcentaje de piezas de influencia inka ronda entre el 10-13\%.

\section{Modelado}

En relación a las técnicas de modelado empleadas para elaborar estos recipientes, hemos registrado macrotrazas vinculables a la superposición de rollos de arcilla en 16 recipientes (11 de Doncellas, dos de Moreta, dos de Queta y uno de Casabindo). Estas macrotrazas consisten en variaciones de espesor verticales $(n=16)$ y aristas o hendiduras de unión de segmentos del cuerpo o de rollos no homogeneizadas en superficie interna y a veces en la externa $(n=10)$. Al tratarse en su mayoría de piezas completas, no se puede registrar el patrón de fractura, que es otra macrotraza importante vinculada a esta técnica de modelado. En tres casos también se observaron depresiones alargadas compatibles con el presionado de las paredes con los dedos. Además, registramos estrías vinculadas al arrastre de material en la adhesión de apéndices y asas al cuerpo $(n=6)$, protuberancias en la superficie interna producidas por la inserción remachada de las asas $(n=4)$, manchas negras en la superficie externa provocadas por variaciones en la atmósfera de cocción $(n=7)$, entre otras macrotrazas aisladas.

Por otro lado, también registramos macrotrazas vinculadas con los acabados de superficie, tales como estrías longitudinales paralelas, en posición horizontal $(n=8)$, vertical $(n=3)$ u oblicuas $(n=2)$, probablemente asociadas al alisado de las superficies. Se observaron caras o facetas longitudinales y paralelas, asociadas al pulido de las superficies, tanto horizontales $(n=22)$, como verticales $(n=15)$ y oblicuas $(n=5)$. Estas últimas se registran únicamente en recipientes abiertos, mientras que las horizontales y verticales, tanto en recipientes abiertos como cerrados. Dos recipientes, uno de Moreta y otro de Doncellas, correspondientes a formas de botellas (aríbalos), presentan perforación producidas pos-cocción, de función indeterminada.

Dos recipientes con apéndices ornitomorfos (cuyas fotos se pueden ver en la Figura $3 \mathrm{~A}$ y B), cocidos en atmósferas reductoras, y una escudilla con asa lateral cocida en atmósfera oxidante incompleta, procedentes de Doncellas, llaman la atención por la irregularidad de sus paredes, de los bordes, el modelado irregular de los apéndices o asa y la abundancia de macrotrazas de modelado que poseen, especialmente el recipiente más pequeño (Figura 3A). Planteamos como posibilidad que puedan haber sido recipientes producidos por aprendices (ya sea jóvenes o adultos) de alfareros/as, que aún no han desarrollado la destreza ni las habilidades motoras para elaborar piezas como otras de las que hemos analizado, que muestran homogeneidad en el espesor de las paredes, simetría y acabados de superficie muy homogéneos (comparar con Figura 3C). Estos recipientes son pequeños o medianos, abiertos, con espesores de paredes, bordes y alturas irregulares, marcas de dedos e instrumentos, todos atributos que han sido mencionados para casos etnográficos de aprendices (ver Vidal, 2019).

\section{Clasificación morfológica y acabados de superficie}

En cuanto a las morfologías identificadas en la muestra analizada, siguiendo el sistema de clasificación de Balfet et al. (1992), 22 recipientes son abiertos, 20 de los cuales corresponden a la categoría escudilla y dos a escudillas hondas (Figura 1). Dentro de las mismas, la mayoría presenta formas hemisféricas $(n=16)$, otras tronco cónicas $(n=4)$ y las dos restantes son fragmentos con perfil indeterminado. Pueden presentar apéndices ornitomorfos $(n=8)$, asas laterales labioadheridas $(n=7)$, o ningún tipo de apéndice $o$ asa $(n=6)$. Una presenta apéndices modelados pequeños como los que se colocan en oposición a los apéndices ornitomorfos, pero se encuentra fracturada, por lo que no sabemos si presentaba también ese tipo de agregado. Cuatro de las que no presentan ningún apéndice o asa, exhiben una pequeña restricción a ambos lados del borde, de forma diametral, posiblemente imitando los recipientes que se elaboraban con calabazas, 
Figura 1. Morfologías abiertas registradas entre las piezas inka relevadas.

Figure 1.Unrestricted morphologies registered amongst the Inka vessels surveyed.

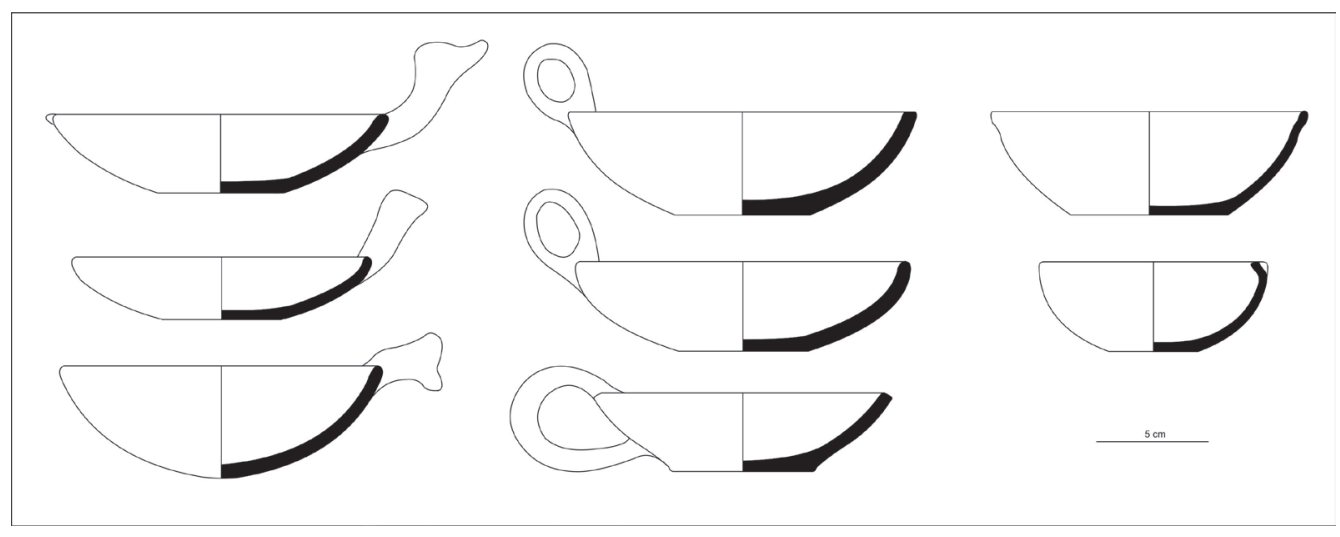

que son abundantes en los contextos funerarios (Krapovickas, 1983). Como mencionamos anteriormente, las agrupamos con las piezas de probable filiación inka por que un par son exactamente iguales (se describen más adelante) y porque no hemos registrado estas formas en otros contextos excavados y datados por nuestro proyecto para momentos previos.

Los tamaños de los recipientes abiertos son variables, con diámetros entre los 6 y $18 \mathrm{~cm}$. Entre las escudillas con apéndices ornitomorfos, los tamaños de los diámetros son más homogéneos, entre 13 y $15 \mathrm{~cm}$, exceptuando una pequeña con un diámetro de $8 \mathrm{~cm}$ (Figura 3B) y características particulares que hemos descrito en la sección anterior. Sus alturas se encuentran entre los 3 y $5 \mathrm{~cm}$. Las otras categorías de formas abiertas presentan mayor variación dimensional.

La mayoría presenta sus superficies pulidas $(n=17)$ y algunos, alisadas $(n=5)$, con $(n=12)$ o $\sin (n=10)$ aplicación de engobes. Siete recipientes presentan además motivos pintados, consistentes en motivos geométricos (círculos concéntricos, espirales, triángulos, cruces), ornitomorfos y motivos de $\mathrm{E}$ invertidas (Figura 2). Los motivos se configuran en forma de franjas bajo el borde sobre la superficie externa, o en la superficie interna en forma concéntrica, en franja longitudinal, en tres paneles paralelos o en forma cuatripartita.

Cinco recipientes abiertos, tres con apéndices ornitomorfos (de Doncellas) (Figura 3) y otros dos sin apéndices con una pequeña constricción en el diámetro (que son exactamente iguales de dimensiones y forma, procedentes de Moreta),

Figura 2. Recipientes abiertos con motivos pintados. A: MLP-Ar-FMM-8173/104 Colección Márquez Miranda (CMM), B: ME-CD No 43-132/-39438-; C: IIT-CD N 1672 (ME N 43-1126).

Figure 2. Unrestricted vessels with painted motifs. A: MLP-Ar-FMM-8173/104 CMM, B: ME-CD No 43-132/39438-; C: IIT-CD No1672 (ME No 43-1126). presentan sus superficies negras (color obtenido por cocción en atmósfera reductora) y pulidas. Es interesante subrayar este par de escudillas pequeñas exactamente iguales (Figura 3D). Otro caso comparable es el de dos escudillas con apéndice ornitomorfo procedentes de Doncellas, que presentan idénticas dimensiones, apéndices, acabados de superficie y motivos pintados en su superficie interna (una de ellas se muestra en la Figura 2B). Autores como Meyers (1975) y Bray (2003) han destacado la frecuencia de pares de piezas abiertas iguales en las tumbas en el área central Inka.

Por otro lado, 21 recipientes son cerrados o restringidos, ocho de los cuales son vasijas y 13 corresponden a la categoría botella (Balfet et al., 1992). Se observa mayor variabilidad de formas y también de tamaños entre los recipientes cerrados que entre los abiertos, aunque la mayor parte de los mismos $(n=10)$ corresponden a formas de botellas de perfil discontinuo o continuo, con cuellos fuertemente evertidos y asas laterales, clasificados como aríbalos. Los perfiles identificados se muestran en la Figura 4.

Dentro de los aríbalos podemos distinguir dos tipos de

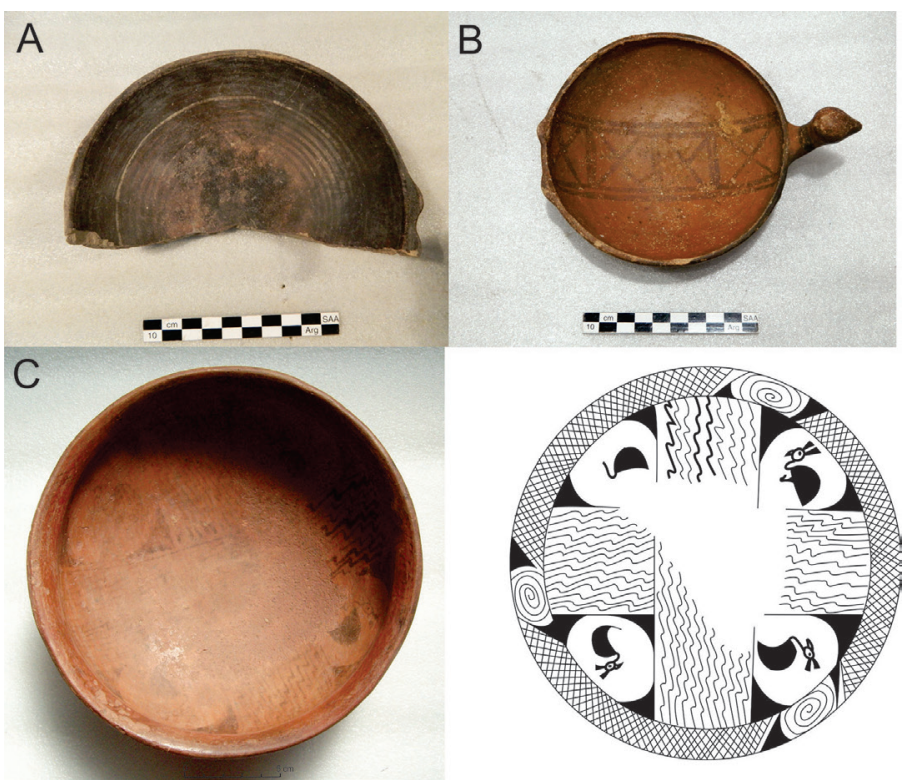


A

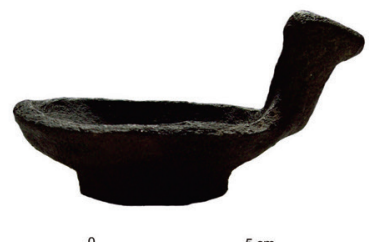

$5 \mathrm{~cm}$

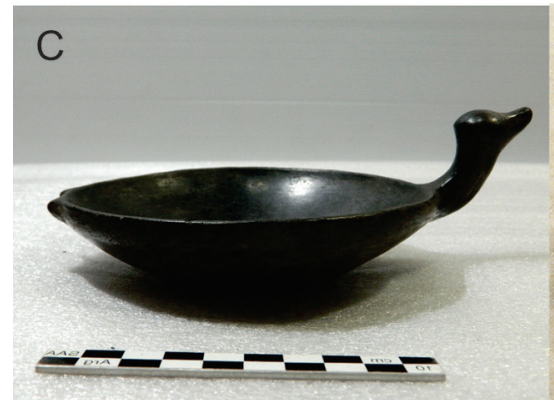

B

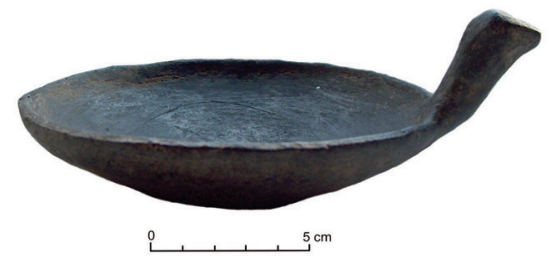

D

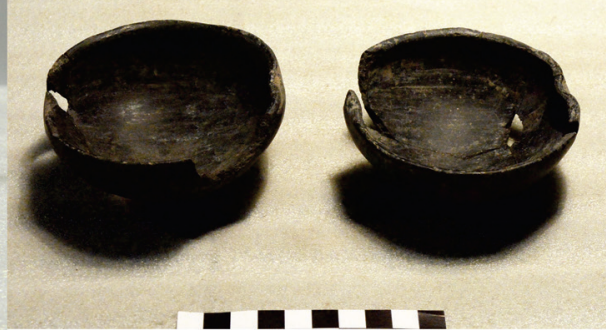

Figura 3. Recipientes abiertos cocidos en atmósferas reductoras. A: IIT-CD No1651 (ME 42-2572); B: IIT-CD No1662 (ME 43-1129); C: ME-CD No43-176; D: MLP-Ar-FMM-8279/261; 8280/262 CMM.

Figure 3. Unrestricted containers fired in reduced atmospheres. A: IIT-CD No1651 (ME 42-2572); B: IITCD No1662 (ME 43-1129); C: ME-CD N43-176; D: MLP-Ar-FMM-8279/261; 8280/262 CMM. formas. Uno $(n=5)$ incluye botellas con perfiles continuos (o con un punto angular muy leve en la unión cuello cuerpo), de cuerpo esférico, cuellos restringidos y bordes muy evertidos, que pueden incluir o no apéndices cónicos (dos perfiles de este tipo se observan a la izquierda de la Figura 4). Presentan también asas verticales opuestas y pueden tener otro apéndice cónico en la porción superior del cuerpo, próximo al cuello. Tres proceden de Doncellas, uno con las superficies negras y pulidas (Figura 6A), otro con engobe rojo pulido en la superficie externa y otro con motivos en negro pintados sobre rojo, consistentes en franjas negras con triángulos cuya base se encuentra apoyada a las mismas (motivo de banderines) (Figura 5A). La morfología y los motivos permiten compararlo al estilo Humahuaca-Inka (Nielsen, 1997, 2007). En los materiales relevados del sitio Moreta, dos de los recipientes cerrados corresponden a esta categoría. Uno presenta engobe rojo pulido y otro, motivos complejos pintados en negro sobre rojo, incluyendo motivos geométricos y ornitomorfos, colocados en la mitad superior del cuerpo, en el cuello, y motivos de zigzag sobre las asas (Figura 5D).

Esta categoría morfológica recuerda las botellas esféricas características del estilo Yavi-chicha, con modificaciones en las asas, que son verticales (o ligeramente oblicuas, como en la Figura 6D) en vez de oblicuas (ver Krapovickas, 1975) y el agregado de cuellos con bordes más evertidos. Los tratamientos de superficie y los motivos pintados en muchos de ellos también remiten a este estilo.

El segundo tipo $(n=3)$ corresponde a botellas con perfiles discontinuos, con bases troncocónicas, asas verticales opuestas, cuellos restringidos y bordes muy evertidos. Pueden presentar apéndices cónicos en el cuerpo. Uno de estos recipientes procede de Doncellas y presenta motivos pintados en negro desleído sobre el engobe rojo pulido, consistentes en líneas delgadas, que lo hacen comparable al estilo Yavi-chicha (Figura 5B). Otro, con engobe rojo pulido en la superficie externa, procede de Moreta. Otro con motivos geométricos pintados en negro sobre rojo, dispuestos en paneles verticales entre las asas, procede de Surugá (Figura 5C).

Estas formas son más comparables a las formas de botellas imperiales, aunque también manufacturadas con atributos tecnológicos locales, incluyendo acabados de superficie y el aspecto macroscópico de las pastas. El ejemplar de Surugá no hemos podido compararlo a los estilos locales
Figura 4. Morfologías cerradas registradas entre las piezas de influencia inka relevadas. A la izquierda, recipientes de la categoría botella, y a la derecha, de la categoría vasija.

Figure 4. Restricted morphologies registered amongst the Inka pottery surveyed. To the left, bottle shapes, and to the right vessels/pots shapes.

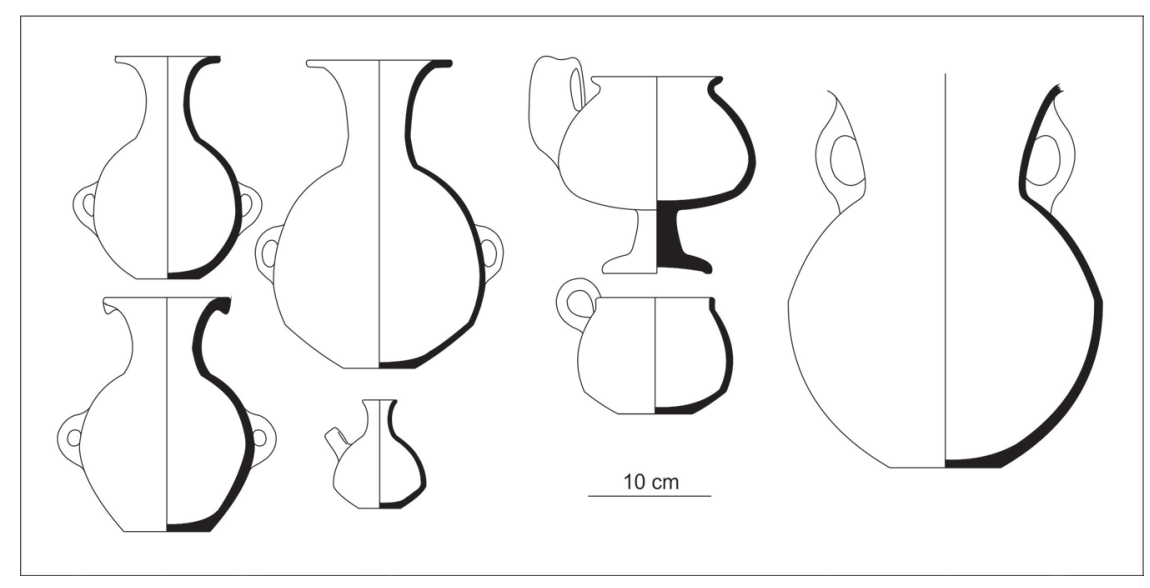

ISSN 1852-060X (impreso) / ISSN 1852-4826 (electrónico) 


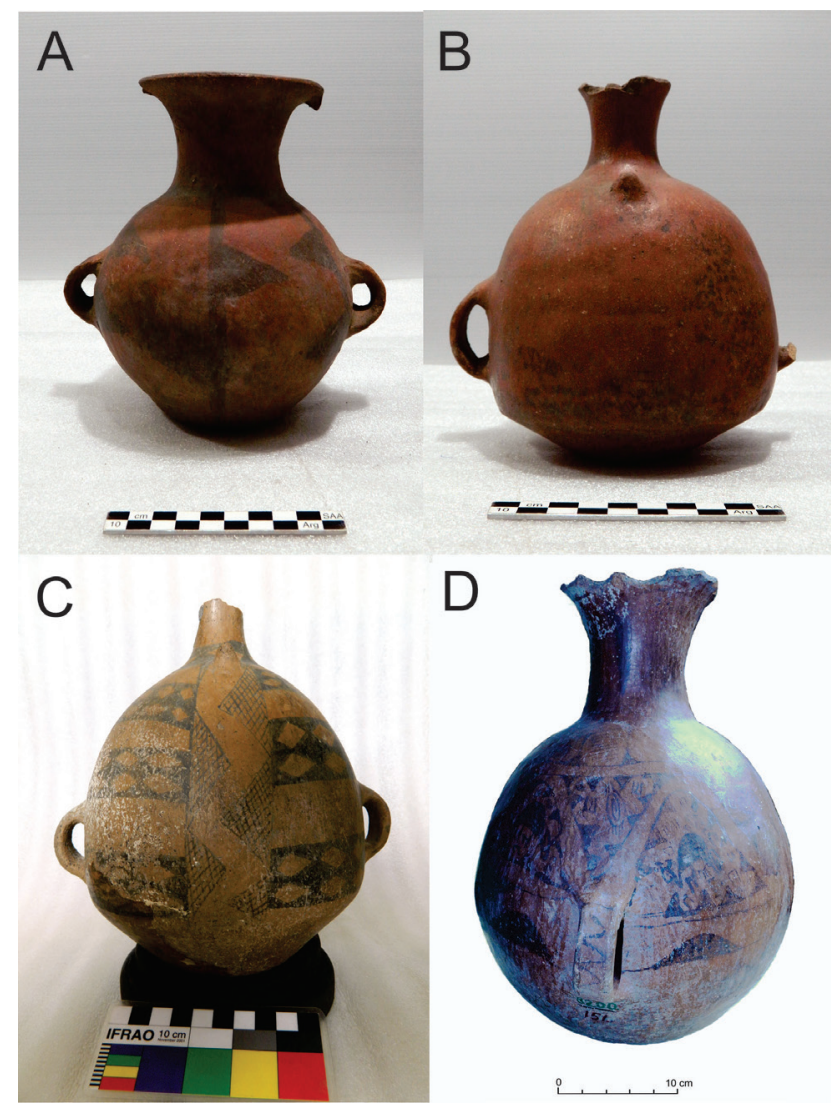

Figura 5. Recipientes de morfología botella (aríbalos) con motivos pintados. A: ME-CD No 43-1131; B: ME-CD N 43-1134; C: MLP-Ar-FPM-3773/4190 Colección Moreno N² (CM N²); D: MLP-Ar-FMM-8200/151 CMM.

Figure 5. Bottle shaped vessels (aribalos) with painted motifs. A: $M E-C D N^{\circ}$ 43-1131; B: ME-CD No 43-1134; C: MLP-ArFPM-3773/4190 Colección Moreno No2 (CM No2); D: MLP-ArFMM-8200/151 CMM.

y, a diferencia de los recipientes anteriores que presentan bases planas, este presenta una base cónica, más similar a la forma de los aríbalos cuzqueños (Bray, 2004). Asimismo, los motivos geométricos dispuestos en registros verticales remiten a los que se hallan en estos últimos (Calderari, 1991), aunque no en las configuraciones identificadas por Bray (2004). Se observa un panel central con triángulos alternos rellenos con reticulados y dos paneles laterales con franjas horizontales de rombos negros que conforman otros en negativo alternados. Esta configuración no se repite en la parte posterior del recipiente.

Los últimos dos recipientes asignables a la categoría de aríbalos consisten en fragmentos, uno de cuello y borde con apéndices cónicos adheridos bajo el borde, con motivos de franjas pintadas en negro sobre el fondo rojo procedente de Doncellas. El otro consiste en fragmentos remontados de cuerpo y asa con la superficie externa engobada y pulida.

Las botellas restantes $(n=3)$ son de tamaño más reducido, presentan una forma similar a los aríbalos del segundo tipo, poseen un asa lateral vertical (tipo "estribo") y son comparables a la forma que se ha denominado botella de cuello largo (Meyers, 1975) o puchuelas (Raffino et al., 1986). Todos ellos presentan las superficies negras (cocciones reductoras) y pulidas (Figura 6B). Uno de estos recipientes procede de Doncellas, otro de Queta, y un fragmento de este tipo de recipiente, de Moreta.

Dentro de las vasijas, dos recipientes completos y uno fracturado (se conserva la base con pie) corresponden a vasijas con pie en pedestal (Figura 6C). Todos proceden de Doncellas y no se ha registrado esta morfología en otro sitio. Presentan diferentes tratamientos de sus superficies externas: uno alisado, otro pulido y el tercero con engobe pulido. No hay grandes diferencias de dimensiones entre los que están completos. Presentan asas subplanas remachadas y sus bases son biconvexas. Otras dos vasijas presentan un punto angular en la porción inferior del cuerpo y asas laterales. Una, con las superficies alisadas, procede de Moreta y la segunda, con engobe pulido en la superficie externa, de Casabindo.

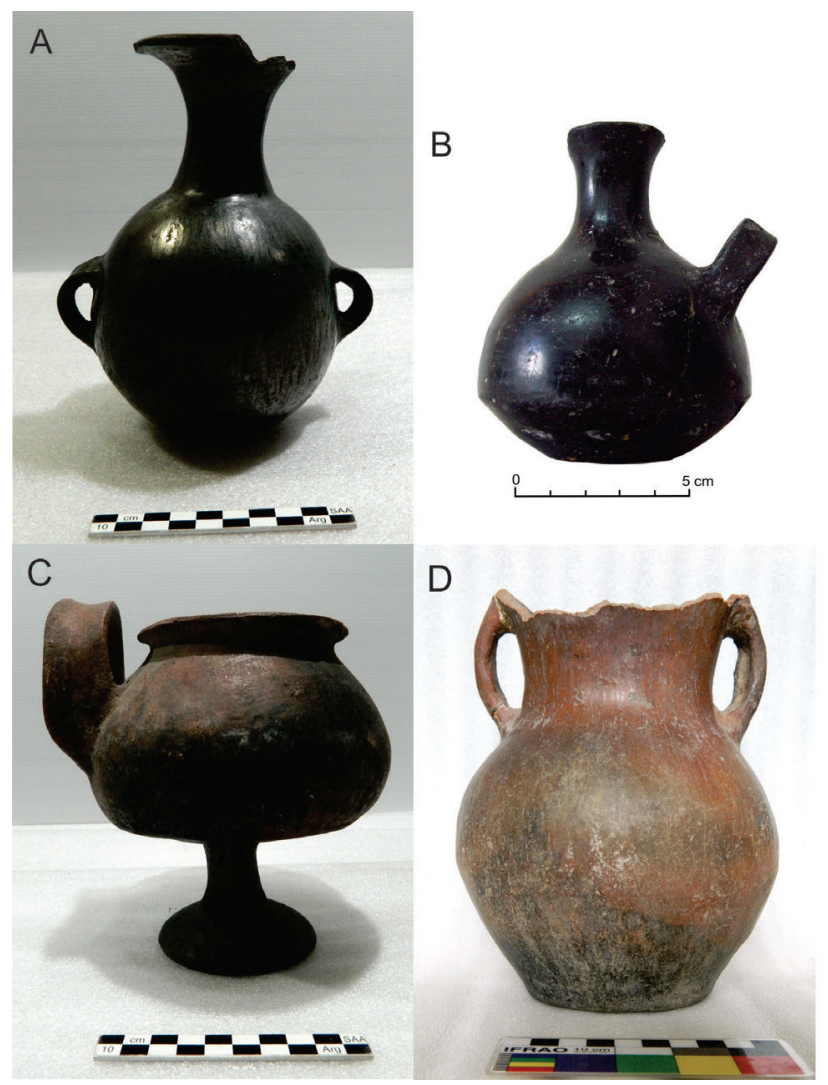

Figura 6. Recipientes de morfología botella con las superficies negras y pulidas (A y B) y de morfología vasija (C y D). A: MECD No 43-173; B: IT-CQ N 2061 (ME 44-1413). C: ME-CD Nº 43-1135; D: MLP-Ar-FPM-3775/4192 CM No2.

Figure 6. Bottle shaped vessels with black polished surfaces (A and $B$ ) and pots/vessels morphologies (C and D). A: ME-CD N ${ }^{\circ}$ 43-173; B: IT-CQ No 2061 (ME 44-1413). C: ME-CD No 43-1135; D: MLP-Ar-FPM-3775/4192 CM No2. 
Los últimos tres objetos correspondientes a la categoría vasija son recipientes de perfil continuo con cuellos altos y asas verticales opuestas colocadas bajo el borde, comparables a las formas definidas en la literatura del área como "pelikes" y que han sido atribuidos a la presencia imperial en el área (Ávila, 2009; Nielsen, 2007). Dos proceden de Doncellas y presentan motivos pintados en negro desleído sobre rojo. En uno de ellos consisten en motivos de líneas curvas rellenos con reticulados o en negro liso, dispuestos en campos horizontales entre las asas y motivos de zigzag verticales sobre las mismas. En el otro se observa en parte un campo rectangular relleno de líneas finas en reticulado, cubierto por hollín. El tercero presenta engobe rojo pulido y es del sitio Casabindo (Figura 6D). Todos ellos son asignables al estilo Yavi-chicha.

Un punto interesante a señalar es la presencia en las asas de uno de estos pelikes y de un aríbaloide (Figura 5D) de motivos de zigzag pintados colocados de manera vertical. Este motivo presenta similitud con los zigzag al pastillaje presentes en la cerámica de los centros mineros coloniales que, a pesar de ser realizados con otra técnica, presentan la misma disposición (Pérez Pieroni, 2018a).

\section{Cocción y huellas de uso}

Como hemos mencionado, parte de las piezas presentan atmósferas de cocción oxidantes $(n=33)$, mientras que otras, presentan atmósferas de cocción reductoras $(n=10)$. En nuestros trabajos previos con cerámica de contextos prehispánicos tardíos de la cuenca sur de Pozuelos y el área de Santa Catalina, este último tipo de cocciones son muy infrecuentes, exceptuando el sitio Moreta, donde hemos hallado fragmentos reducidos y pulidos (Angiorama et al., 2018; Pérez Pieroni, 2018b).

La mayor parte de los recipientes analizados no muestra huellas o marcas que se puedan vincular a su uso, exceptuando algunas de las piezas cerradas. Entre las vasijas con pie en pedestal (en un fragmento de pie y un recipiente completo) se registran manchas y depósitos oscuros por exposición al fuego. En el caso del recipiente completo en el área opuesta a la única asa. Meyers (1975) menciona que las manchas por exposición al fuego son frecuentes en este tipo de recipientes y Bray (2003) señala su uso probable para la cocción de alimentos. También se observaron machas y depósitos oscuros en dos de las formas que hemos identificado como pelikes.

\section{Distribución y vinculación con los estilos regionales}

En la Tabla 2 se puede observar cómo se distribuyen las categorías morfológicas de recipientes identificados en los diferentes sitios analizados. Si bien la cantidad de piezas inkaicas para el total de recipientes relevados es reducida y no permite formular tendencias importantes, es destacable que las vasijas con pie en pedestal sólo estén presentes en Doncellas y no haya ejemplares en otros sitios. El resto de morfologías identificadas se reconocen en diferentes sitios y en aquellos que presentan un número de piezas algo abundante, se puede identificar un repertorio de formas inkaicas que incluye principalmente escudillas, seguidas por botellas y/o, en menor medida, vasijas. No hemos registrado variaciones en la distribución de las botellas de perfil continuo o discontinuo.

Un porcentaje importante de recipientes $(n=15)$ pueden relacionarse al estilo Yavi-chicha, tanto por sus acabados de superficie y los motivos pintados, como por las pastas compactas rojas (2,5YR 5/6, 6/6; 5YR 5/4), o marrón rojizo $(2,5 \mathrm{YR} 5 / 4,6 / 4)$, con presencia de litoclastos blancos y rosados, que en materiales fragmentarios hemos podido identificar a nivel petrográfico como litoclastos pelíticos (Pérez Pieroni, 2015, 2018b) y que han sido descritos como una característica tecnológica de este estilo (Cremonte, 2014; Krapovickas, 1975; Pérez Pieroni, 2015).

Por otro lado, planteamos la posibilidad de que los recipientes con superficies reducidas y pulidas $(n=8)$ también pueden vincularse a este estilo, ya que en nuestros trabajos hemos identificado la presencia de recipientes con estos acabados de superficie asociado a cerámica Yavi-chicha en momentos previos a la conquista Inka y con pastas petrográficamente comparables a las que

\begin{tabular}{|c|c|c|c|c|c|c|c|c|}
\hline & \multicolumn{3}{|c|}{ Piezas abiertas } & \multicolumn{5}{|c|}{ Piezas cerradas } \\
\hline & $\begin{array}{l}\text { Sin asas/ } \\
\text { apéndices }\end{array}$ & $\begin{array}{l}\text { Con apéndice } \\
\text { ornitomorfo }\end{array}$ & $\begin{array}{l}\text { Con asa } \\
\text { lateral }\end{array}$ & $\begin{array}{l}\text { Vasija con pie } \\
\text { en pedestal y } \\
\text { asa lateral }\end{array}$ & Pelike & $\begin{array}{l}\text { Vasija con } \\
\text { base tronco } \\
\text { cónica }\end{array}$ & Aríbalos & 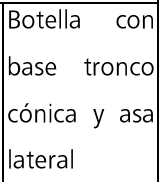 \\
\hline Doncellas & 4 & 6 & 1 & 3 & 2 & 0 & 5 & 1 \\
\hline Moreta & 2 & 2 & 1 & 0 & 0 & 1 & 4 & 1 \\
\hline Casabindo & 0 & 0 & 0 & 0 & 1 & 1 & 0 & 0 \\
\hline Surugá & 0 & 0 & 0 & 0 & 0 & 0 & 1 & 0 \\
\hline Cochinoca & 0 & 0 & 1 & 0 & 0 & 0 & 0 & 0 \\
\hline Queta & 0 & 1 & 3 & 0 & 0 & 0 & 0 & 1 \\
\hline $\begin{array}{ll}\text { Pukará de } \\
\text { Rinconada }\end{array}$ & 0 & 0 & 1 & 0 & 0 & 0 & 0 & 0 \\
\hline TOTAL & 6 & 9 & 7 & 3 & 3 & 2 & 10 & 3 \\
\hline
\end{tabular}

Tabla 2. Distribución de las formas identificadas por sitio.

Table 2. Distribution of the identified shapes by site. 
hemos analizado para este estilo (Pérez Pieroni, 2018b). Cremonte (2007) también identifica pastas comparables en recipientes con superficies con los mismos tratamientos en Agua Hedionda. La presencia de recipientes cocidos en atmósferas reductoras que presentan rasgos compatibles con aquellos producidos por aprendices, mencionados previamente, podría reforzar este punto. Sin embargo, se hace necesaria la ampliación de la muestra de pastas analizadas petrográficamente en este tipo de materiales.

Otros dos recipientes corresponden al aríbalo HumahuacaInka que ya hemos mencionado $(n=1)$ y a una escudilla con cruces pintadas en negro sobre el engobe rojo en la superficie interna, procedente de Cochinoca, que también presenta inclusiones de litoclastos blancos visibles macroscópicamente. Todos ellos son recipientes con características morfológicas y de superficies que han sido señaladas como frecuentes en época Inka en la Quebrada de Humahuaca (Nielsen, 1997, 2007). El resto de los objetos que hemos descrito presentan acabados de superficie y motivos pintados que no podemos relacionar a estilos locales o de zonas vecinas y que desconocemos su origen $(n=4)$, o presentan superficies alisadas o pulidas $(n=12)$ o se encuentran fragmentados o meteorizados $(n=2)$ y no hay elementos hasta ahora que permitan suponer una manufactura regional o no. Los que presentan inclusiones visibles a nivel macroscópico (con lupa de mano de 20X), exhiben mineraloclastos de cuarzo, micas y litoclastos de rocas sedimentarias finas de diferentes colores. En la muestra de pastas analizadas por nosotros en sitios de la puna de Jujuy hemos registrado inclusiones similares (Pérez Pieroni, 2015, 2018b), aunque a esta escala el tipo de comparaciones que se pueden hacer es muy general.

\section{Discusión}

La tecnología de manufactura de la cerámica Inka:

A lo largo de la sección anterior, hemos descrito hasta el nivel que lo permite el estudio de colecciones de museo, atributos de recipientes cerámicos de probable filiación inka, vinculados a su manufactura y morfología principalmente. La mayor parte presentan atributos tecnológicos, acabados de superficie y elementos iconográficos que son comparables a los estilos descritos para la Puna, particularmente al estilo Yavi-chicha (Ávila, 2009; Cremonte, 2014; Krapovickas, 1975; Pérez Pieroni, 2015). Las macrotrazas de modelado registradas son comparables con las que hemos identificado para momentos previos para el material fragmentario y de colecciones (Pérez Pieroni, 2015, 2018b) e incluyen aquellas vinculadas al modelado de las piezas por superposición de rollos de arcilla, el estirado con los dedos, el modelado de diferentes segmentos de piezas cerradas en etapas, la inserción remachada de asas y otras asociadas a los acabados de superficie. También estos acabados de superficie, las macrotrazas de alisado y pulido, los engobes y la aplicación de pintura negra son en todo similares a los de la cerámica local de momentos previos. Si bien no es posible hacer análisis en fractura fresca y petrográficos sobre las pastas de recipientes cerámicos de colección, el aspecto macroscópico de las mismas y sus inclusiones son afines a las observadas para contextos tardíos pre-inkaicos.

Dentro de las morfologías inkas identificadas, los aríbalos presentan una variabilidad de formas que hemos dividido en dos grupos, uno con perfiles continuos, que presentan mayor similitud con recipientes cerrados del estilo Yavi-chicha de momentos previos, y otro con perfiles discontinuos, que imitan en mayor grado las formas imperiales. Del total, la mitad presentan motivos pintados en sus superficies.

Para las escudillas, hay cierta variedad de formas y además, se evidencian diferentes grados de cuidado o destreza en la ejecución, tanto de aquellas con apéndices ornitomorfos como de las que presentan asa lateral. Entre estas, se observa una variabilidad amplia de acabados de superficie, tales como alisados, engobes, superficies negras pulidas y la aplicación de elementos de diseño pintados en un tercio de ellas aproximadamente (32\%). A pesar de la variabilidad, dentro de la categoría de platos con apéndices ornitomorfos hemos registrado cierta homogeneidad en las dimensiones, lo cual ha sido señalado en otros sitios del NOA (por ej., ver Coloca, 2020).

Para todos los recipientes relevados, algunos diseños pintados remiten a los elementos presentes previamente en la cerámica Yavi-chicha, otros se incorporan a este estilo en este momento, como los ornitomorfos estilizados, las cruces y las E invertidas (que son motivos que se han identificado dentro del estilo Inka Paya o Casa Morada polícromo, ver Calderari, 1991; Williams, 2004), y otros surgen como novedades de origen que aún no podemos precisar. Sin embargo, un número importante de recipientes no presentan motivos pintados en sus superficies, aunque es frecuente observar un acabado cuidado mediante engobe y pulido.

Otro punto a subrayar es el de los recipientes de formas imperiales negros pulidos. Su presencia también ha sido señalada en otros sitios inka del NOA, junto a la cerámica Yavi-chicha de formas inka e Inka Pacajes (por ej., Coloca, 2020; Cremonte et al., 2010). Planteamos la posibilidad de que, en el caso de la Puna, sean de manufactura regional, dado que en Moreta hemos hallado fragmentos negros pulidos con pastas petrográficamente comparables a las Yavi-chicha en contextos datados previamente a la expansión imperial. Para el sitio Agua Hedionda, un sitio inka ubicado en los valles meridionales de Jujuy, Cremonte (2007) señala la presencia de un mismo tipo de pasta, con inclusiones de sedimentitas blancas alteradas, en los fragmentos Yavi-chicha y negros pulidos. Sumamos también la posibilidad señalada en la sección anterior de que algunas de las escudillas con apéndices ornitmorfos relevadas, cocidas en atmósferas reductoras, hayan sido elaboradas por aprendices. 
Es significativo que las piezas de forma Inka sean escasas en un repertorio compuesto mayormente por recipientes de formas locales, a pesar de que no sabemos cuáles de estas últimas fueron contemporáneas con las inkaicas. Por otro lado, que las mismas hayan sido manufacturadas empleando las tradiciones tecnológicas regionales, sin que en esta escala de análisis se evidencien cambios significativos más allá de la introducción de ciertas formas o de ciertos elementos de diseños pintados, también es relevante. Incluso, en algunas botellas se emplean las formas anteriores, agregando únicamente un cuello y un borde evertido para relacionarlas a la forma de aríbalo.

Quizás todo ello esté mostrando que el control estatal en la manufactura cerámica de esta porción del Tawantinsuyu no fue muy marcado, particularmente en lo referente a su tecnología y los grupos de artesanos y artesanas que la producían. También puede estar indicando una alta valoración por parte del imperio de las tradiciones tecnológicas y repertorios cerámicos locales. Otros autores han destacado la variabilidad de estrategias y niveles de injerencia empleados por los inkas en el control de la producción alfarera para los intereses del imperio, resaltando casos similares a lo que notamos (Alconini, 2013; D'Altroy et al., 1998; Hayashida, 1999). Se ha señalado (Costin, 2018; Williams, 2000, 2004) que buena parte de la cerámica inka fue producida para consumo regional por grupos de artesanos y artesanas que produjeron en sus propios estilos, más allá de la amplia circulación que tuvieron algunos recipientes de estilo cuzqueño. La variación de la producción cerámica de una provincia a otra fue resultado de que el estado tuvo que depender de ceramistas locales y de la limitada circulación de los recipientes por su peso y fragilidad (Williams, 2004).

Si bien el control pudo no ser muy marcado en las secuencias de producción cerámica, es posible que haya habido una mayor intervención estatal en qué tipos de objetos se manufacturaban o en ciertos aspectos de la manufactura como la calidad de los objetos terminados (Costin, 2018). A pesar de que el número de recipientes relevados es reducido, la regularidad en los tamaños señalada para las escudillas con apéndices ornitomorfos y para las vasijas con pie de compotera pueden estar apoyando esta posibilidad.

Uso y distribución de recipientes inkaicos:

Dentro de las morfologías que hemos identificado, hallamos aquellas que se han señalado como más frecuentes en el ámbito de las provincias, tales como aríbalos, escudillas y, en menor medida, botellas de cuello largo y asa lateral (puchuelas) y ollas con pie de compotera. Estas formas han sido asociadas a rituales y festejos, al servicio de bebidas como la chicha, y son fácilmente reconocibles y vinculables a la presencia Inka (Bray, 2003; Costin, 2018; Hayashida, 1999; Meyers, 1975; Williams, 2004).

Las formas identificadas presentan, en general, tamaños pequeños y fácilmente transportables, exceptuando un par de aríbalos que son de dimensiones mayores. Incluso, los recipientes con evidencias de exposición al fuego y para los cuales podemos suponer su uso en la preparación de alimentos y/o bebidas en el calor, como las ollas con pie de compotera, su tamaño pequeño resulta llamativo y sólo podrían haber sido empleadas para preparar una cantidad limitada de alimentos (Bray, 2003; Meyers, 1975). Bray (2003) plantea que, dado que es el único recipiente para cocción en un estilo imperial distintivo que fue ampliamente distribuido, y dado el conservadurismo que se registra en general para los recipientes vinculados a la cocción de alimentos, lo que se haya preparado en estas ollas seguramente tuvo una importancia marcada y habría involucrado también la imposición de algunas prácticas culinarias. Sin embargo, dado el bajo número en que fueron halladas (tres recipientes en total en un único sitio) estas imposiciones no serían tan marcadas en nuestra área.

Se ha planteado que los aríbalos habrían servido para contener líquidos, particularmente chicha, lo que se sustenta en su morfología, especialmente en la fuerte restricción del diámetro mínimo (Bray, 2003). La morfología de las puchuelas, con cuellos largos y diámetros mínimos pequeños, también cumplen con los requerimientos morfológicos de contenedores de líquidos, aunque en cantidades menores (Bray, 2003). Los recipientes abiertos, que posibilitan un acceso irrestricto a su contenido, pudieron ser empleados en el servicio de alimentos y bebidas (Bray, 2003), siendo aquellos un poco más profundos los que posibilitan la segunda opción. Algunos aparecen en pares en las colecciones y son las formas más abundantes que hemos registrado.

Seguramente, estas piezas con formas relacionadas a contener, transportar o almacenar y servir alimentos y bebidas, estuvieron vinculadas con los principios de reciprocidad y hospitalidad que el Tawantinsuyu empleó en su trama de relaciones políticas a lo largo del imperio para incorporar a las elites locales a la burocracia estatal y el establecimiento de alianzas (Adán y Uribe, 2005; Alconini, 2008; Bray, 2003; Cremonte et al., 2010; Williams, 2000, 2004; entre otros). Como han señalado algunos de estos autores (Bray, 2013; Costin, 2018; Cremonte et al., 2010), el repertorio cerámico imperial fue un componente integral de las estrategias estatales de legitimación y control. Su presencia tras ser utilizado y entregado en estos eventos pudo funcionar como un recordatorio del poder y generosidad del estado por mucho tiempo (Costin, 2018). Por otro lado, las actividades de elaboración de alimentos y bebidas son tareas que se señalan frecuentemente como femeninas, por lo que las formas distribuidas por el imperio indican la importancia de las mujeres en la política imperial, como lo ha remarcado Bray (2003).

Los recipientes analizados fueron distribuidos y/o empleados en sitios donde la ocupación inka se 
superpone a importantes asentamientos previos (Moreta, Doncellas, Pukará de Rinconada, Queta) y pasaron a constituir parte de los acompañamientos funerarios. La dominación inka a nivel regional probablemente incluyó la integración de estos poblados mediante la implantación de elementos arquitectónicos en algunos de ellos, la circulación de objetos, como los cerámicos, y otras estrategias de dominación y negociación que pudieron involucrar diferentes prácticas sociales y materialidades, insertándose de diferentes formas en las vidas cotidianas (Acuto, 1999). La baja cantidad de recipientes cerámicos inkaicos en relación a los de estilos locales y el hecho de que hayan sido incluidos en algunas tumbas, permite pensar que las relaciones y prácticas involucradas en tales estrategias no fueron homogéneas.

De los sitios analizados que contienen un número abundante de piezas Inka, el que posee un porcentaje algo mayor es Moreta, que por otro lado, en trabajos previos hemos destacado por su alta frecuencia de cerámica Yavichicha en relación a otros sitios importantes de la Puna, como el Pukará de Rinconada, Doncellas y Queta y que se trataría del asentamiento chicha más meridional que se conoce hasta la fecha (Angiorama et al., 2017). Además, presenta un sector defensivo, desde donde se visualiza el Pukará de Rinconada (que habría sido ocupado por los Casabindo-Cochinoca según autores como Albeck, 2007 y Krapovickas, 1983), por lo que es sugerente que los inkas hayan instalado estructuras y circulado recipientes cerámicos de formas imperiales en dos sitios estratégicos.

La relación de la producción de cerámica de formas inka y la tradición tecnológica que hemos vinculado al estilo Yavichicha son notables en la puna de Jujuy, y no observamos cerámica inka manufacturada en otros estilos regionales, como el Casabindo. Esto ya había sido señalado por autores previos (Ávila, 2009; Krapovickas, 1983; Raffino et al., 1986) y, como mencionamos previamente, seguramente indica la alta valoración que el estado le dio a este estilo particular (Williams, 2004). El estilo Inka Paya o Casa Morada polícromo, que tiene una amplia circulación en este período, ha sido vinculado con el Yavi Chico polícromo (Ávila, 2009; Krapovickas, 1983). La cerámica del estilo Yavi-chicha (incluyendo Inka Paya) tuvo una presencia muy amplia en este momento, llegando a sitios del Valle Calchaquí, del Valle de Yokavil, posiblemente a través de mitmakuna que produjeron esta cerámica en esos mismos valles (Cremonte, 2014; Cremonte et al., 2010; D'Altroy et al., 1998; Marchegiani, 2012; Williams, 2000; Williams y Cremonte, 1997); a los valles orientales del norte de la actual provincia de Salta (Ventura y Oliveto, 2014) y como elementos ya manufacturados al norte de Chile (Adán y Uribe, 2005; Uribe y Agüero, 2005), entre otros. La posibilidad de la producción de cerámica Yavichicha en momentos inkaicos por mitmakuna también ha sido postulada para algunos sitios de la Quebrada de Humahuaca y los valles meridionales de Jujuy (Cremonte, 2007, 2014; Fernández Do Río, 2010).
Junto con esta cerámica, también se habrían distribuido recipientes en el estilo Inka Pacajes, y se ha propuesto que tanto el Yavi-chicha, como el Inka Paya y el Inka Pacajes habrían sido estilos muy valorados por los inkas, que se dispersaron por el NOA durante la expansión estatal como parte de las relaciones de reciprocidad, intercambio, producción, etc. (Cremonte et al., 2015, 2010; Williams, 2004). Incluso, a partir del estudio de las pastas, se ha postulado una vinculación entre las producciones de estos estilos (Cremonte et al., 2015). Hemos hallado fragmentos de recipientes abiertos con las llamitas estilizadas características de esta cerámica entre materiales fragmentarios tanto en Moreta como en otros sitios con evidencia Inka en el área de Santa Catalina.

A pesar de estos diferentes casos en que se ha planteado la distribución de la cerámica Yavi-chicha como parte del traslado de mitmakunas chichas a diferentes regiones del imperio, no creemos que este sea el caso en el área estudiada por nosotros, donde los asentamientos vinculados a los chicha preceden la expansión del Tawantinsuyu. Para el caso de Moreta, por ejemplo, la arquitectura doméstica de características chicha ha sido datada en el sector de recintos de viviendas a inicios del segundo milenio de la era, lo que constituye las evidencias más tempranas conocidas hasta el momento para este patrón arquitectónico a nivel regional e indica su presencia previa a la expansión imperial, descartando el traslado de estos grupos para cumplir tareas en el tambo (Angiorama et al., 2018).

En zonas vecinas, dentro del área del estilo Yavi-chicha, se registran formas y elementos similares asociados a la expansión imperial. Por ejemplo, en el altiplano de Sama, se registran escudillas que pueden presentar apéndices ornitomorfos con características tecnológicas que las relacionan con este estilo, y fragmentos con elementos iconográficos de influencia inkaica, como las E invertidas y los motivos ornitomorfos, combinados con elementos Yavi (Beierlein de Gutierrez, 2009). En la puna de Santa Catalina la presencia de cerámica Inka con elementos similares a los descritos, se asocia con las ocupaciones Yavi-chicha en Timón Cruz y a un tambo Inka en Santa Catalina (Nielsen et al., 2015; Pérez Pieroni, 2015). Sin embargo, en otras áreas como el Río San Juan Mayo, donde se registra una presencia importante de sitios habitacionales vinculados a poblaciones con cerámica Yavi-chicha, se postula un abandono de los poblados hacia momentos del Tawantinsuyu, quizás vinculado con el traslado de poblaciones (Nielsen et al., 2015).

\section{Conclusiones}

En base a los análisis presentados, podemos postular que la cerámica inka de la puna de Jujuy estudiada en este trabajo fue producida regionalmente, tal como señalamos en la sección anterior. Los materiales cerámicos, junto con otros elementos que tradicionalmente se analizan para 
abordar la presencia inka en el NOA, como la arquitectura, sectores productivos, etc., muestran relaciones diferentes entre este imperio y las poblaciones que habitaban en los distintos sectores de la puna de Jujuy. La relación con aquellos grupos que produjeron la cerámica Yavi-chicha fue más intensa, probablemente involucrando incluso el traslado de poblaciones.

Sin embargo, aunque es factible que se haya intensificado la producción de cerámica en estos momentos, las tradiciones tecnológicas que podemos reconstruir a partir de los materiales de colecciones no se vieron significativamente afectadas. Las comunidades de alfareros y alfareras que produjeron estos materiales continuaron desplegando los saberes técnicos que desarrollaron durante todo el período prehispánico tardío. Incluso, buena parte del material cerámico empleado seguramente continuó siendo el mismo de momentos anteriores.

Los elementos incorporados fueron principalmente morfologías que se encuentran a lo largo de todo el imperio, tales como escudillas, botellas y ollas con pie, con algunos elementos de diseño novedosos. El control imperial pudo estar enfocado en la producción de este tipo de formas y en los tamaños de algunas de ellas. Estas formas tan reconocibles seguramente operaron como índices de la presencia imperial en la trama de las diferentes relaciones de negociación desplegadas por los inkas.

Los avances realizados en los materiales de colección servirán como base para continuar estudiando material fragmentario de excavaciones recientes en Pukará de Rinconada y Moreta. Esperamos que ello permita comparar algunas de las tendencias observadas con materiales procedentes de contextos diferentes (por ejemplo, domésticos) y profundizar en aspectos de la manufactura y su vinculación con las tradiciones tecnológicas previas con información como la que provee el análisis de pastas cerámicas. Por otro, podremos ahondar en el uso de los recipientes mediante el estudio de huellas de uso y de otras vías directas como el análisis de microrrestos. La distribución de estos recipientes en bajas cantidades y de formas aparentemente no homogéneas es otro aspecto que requiere ser profundizado, a fin de contribuir a nuestro entendimiento del tipo de relaciones y prácticas sociales que fueron desplegadas dentro de las estrategias de dominación imperial.

San Miguel de Tucumán, septiembre de 2020

\section{Agradecimientos}

Agradezco a las instituciones y a las personas dentro de ellas que, con generosidad, posibilitaron y facilitaron mi trabajo de relevamiento en sus colecciones y por permitirme publicar las fotografías de los recipientes: en el Instituto Interdisciplinario Tilcara, a Pablo Ochoa y Armando Mendoza; en el Museo Etnográfico "Juan B.
Ambrosetti" a Mónica Berón, Gabriela Ammirati, Juan Manuel Estevez y Alejandra Reynoso; en el Musée du Quai Branly a Paz Nuñez Regueiro y Marie-Laurence Bouvet; en el Museo de Ciencias Naturales de la UNLP a Mariano Bonomo, Ana Igareta, Jorge Kraideberg, Gabriel Alarcón, Guillermina Couso y Jorgelina Collazo. Un agradecido recuerdo a Rodolfo Raffino y a Marina Marchegiani. A Carlos Angiorama por su lectura crítica. Las investigaciones realizadas han sido financiadas gracias a subsidios PIP CONICET, PICT FONCYT y PIUNT.

\section{Referencias citadas}

Acuto, F. A. (1999). Paisaje y dominación: la constitución del espacio social en el Imperio Inka. En A. Zarankin \& F. A. Acuto (Eds.), Sed Non Satiatia. Teoría Social en Arqueología Latinoamericana Contemproránea (pp. 33-75). Ediciones del Tridente.

Adán, L., \& Uribe, M. (2005). El dominio inca en la localidad de Caspana: Un acercamiento al pensamiento político andino (río Loa, norte de Chile). Estudios Atacameños, 29, 41-66.

Albeck, M. E. (2007). El Intermedio Tardío: Interacciones económicas y políticas en la Puna de Jujuy. En V. Williams, B. Ventura, A. Callegari \& H. Yacobaccio (Eds.), Sociedades Precolombinas Surandinas (pp. 125-145). Edición del autor.

Albeck, M. E., Zaburlin, M. A., \& Menacho, K. A. (2007). Espacios productivos y simbólicos. La dominación inca en Casabindo. Actas del XVI Congreso Nacional de Arqueología Argentina, Tomo II (pp. 549-554). Universidad Nacional de Jujuy.

Alconini, S. (2008). Dis-embedded centers and architecture of power in the fringes of the Inka empire: New perspectives on territorial and hegemonic strategies of domination. Journal of Anthropological Archaeology, 27, 63-81.

Alconini, S. (2013). El territorio Kallawaya y el taller alfarero de Milliraya: evaluación de la producción, distribución e intercambio interregional de la Cerámica inka provincial. Chungara, 45(2), pp. 277-292.

Alfaro, L. C. (1983). Investigaciones arqueológicas en la cuenca del Río Doncellas (Provincia de Jujuy). Integración de la Puna Jujeña a los centros cúlticos andinos. Relaciones de la Sociedad Argentina de Antropología, XV, 25-47.

Alfaro, L. C. (1988). Investigación en la cuenca del Río Doncellas. Dpto. de Cochinoca - Provincia de Jujuy. Reconstrucción de una Cultura olvidada en la Puna Jujeña. Imprenta del Estado de la Provincia de Jujuy.

Alfaro, L., \& Suetta, J. (1970). Nuevos aportes para el estudio del asentamiento humano en la puna de Jujuy. Revisión del Pucará de Rinconada. Antiquitas, 10, 1-10. 
Angiorama, C. I., Pérez Pieroni, M. J., \& Becerra, M. F. (2017). Moreta, "pueblo de yndios chichas y tambo del ynga" (Puna de Jujuy, Argentina). Estudios Atacameños, 55, 163-181.

Angiorama, C. I., Becerra, M. F., Coronel, A., Franco Salvi, V., Giusta, M., Lauricella, M. S., Pérez Pieroni, M. J., \& Rodríguez Curletto, S. (2018). Historia ocupacional y prácticas productivas en Moreta (Puna de Jujuy, Argentina) durante tiempos prehispánicos y coloniales. Relaciones de la Sociedad Argentina de Antropología, XLIV(1), 13-34.

Ávila, M. F. (2009). Interactuando desde el estilo. Variaciones en la circulación espacial y temporal del estilo alfarero yavi. Estudios Atacameños, 37, 29-50.

Balfet, H., Fauvet-Berthelot, M. F., \& Monzón, S. (1992). Normas para la Descripción de Vasijas Cerámicas. Centre D’Études Mexicaines et Centraméricaines.

Beierlein de Gutierrez, M. (2009). La cerámica prehispánica tardía del Altiplano de Sama y su relación con las regiones vecinas: Una aproximación arqueológica a la complejidad cultural de la macrorregión Noroeste Argentino-Sur de Bolivia. Estudios Atacameños, 37, 51-61.

Boman, E. (1908). Antiquités de la Région Andine de la République Argentine et du Désert d'Atacama (Tomo II). Librairie H. Le Soudier, Imprimerie Nationale.

Bourdieu, P. (1993). El Sentido Práctico. Taurus.

Bray, T. L. (2003). To Dine Splendidly. Imperial Pottery, Commensal Politics and the Inca State. En T. L. Bray (Ed.), The Archaeology and Politics of Food and Feasting in Early States and Empires (p. 93-142). Kluwer Academic/Plenum Publishers.

Bray, T. L. (2004). La alfarería imperial Inka: una comparación entre la cerámica estatal del área de Cuzco y la cerámica de las provincias. Chungara, 36(2), pp. 365-374.

Calderari, M. (1991). Estilos cerámicos incaicos de La Paya. Actas del XI Congreso Nacional de Arqueología Chilena, Tomo II (pp. 151-164). Sociedad Chilena de Arqueología.

Calderari, M., \& Williams, V. (1991). Reevaluación de los estilos cerámicos incaicos en el Noroeste Argentino. En El imperio Inka. Actualización y perspectivas y registros arqueológicos y etnohistóricos, Comechingonia, II, 73-96.

Casanova, E. (1943). Comunicación acerca del Yacimiento de Doncellas. Boletín de la Sociedad Argentina de Antropología, 5-6, 80-81.

Coloca, F. (2020). La ocupación Inca en la Cuenca de Ratones, Puna de Salta, Argentina. Primeras aproximaciones sobre el análisis de la cerámica de los sitios Cueva Inca Viejo y Abra de Minas. Chungara, 52(2), 261-283.

Costin, C. L. (2018). Gender and Status in Inca Textile and Ceramic Craft Production. En S. Alconini \& A. Covey (Eds.), The Oxford Handbook of the Incas (pp. 283302). Oxford University Press. https://doi.org/10.1093/ oxfordhb/9780190219352.013.14
Cremonte, M. B. (2007). Aspectos económicos y políticos con relación a la ocupación inca en los valles meridionales de Jujuy, Argentina. En V. Williams, B. Ventura, A. Callegari \& H. Yacobaccio (Eds.), Sociedades Precolombinas Surandinas (pp. 109-124). Artes Gráficas Buschi.

Cremonte, M. B. (2014). El estilo ceramico yavi-Chicha en instalaciones inkaicas del noroeste Argentino. En C. Rivera Casanova (Ed.), Las pastas como posible marcador identitario. Ocupación Inka y dinámicas regionales en los Andes (Siglos XV-XVII) (pp. 223-245). Instituto Francés de Estudios Andinos.

Cremonte, M. B., Maro, G., \& Díaz, A. M. (2015). Acercamiento a la producción y distribución del estilo Inca Pacajes. Un estudio arqueométrico de las pastas. Chungara, 47(3), 387-400

Cremonte, M. B, Williams, V., \& Díaz, A. (2010). Cuencas de Angastaco-Molinos. Una aproximación al control Inca a partir de la producción cerámica. En J. R. Bárcena \& H. Chiavazza (Eds.), Actas del XVII Congreso Nacional de Arqueología Argentina, Tomo III (p. 1285-1290). Facultad de Filosofía y Letras, Universidad Nacional de Cuyo.

D'Altroy, T. N., Lorandi, A. M., \& Williams, A. M. (1998). Ceramic Production and use in the Inka Political Economy. MASCA Research papers in Science and Archaeology, Supplement to Vol. 15, 284-312.

Fernández Do Río, S. (2010). Dominio Inca y relaciones coloniales en el sector medio de la Quebrada de Humahuaca. Actas del XVII Congreso Nacional de Arqueología Argentina, Tomo II (p. 789-794). Facultad de Filosofía y Letras, Universidad Nacional de Cuyo.

García Roselló, J., \& Calvo Trías, M. (2013). Making Pots. El modelado de la cerámica y su potencial interpretativo. BAR International Series 2540. Archaeopress.

González, L., \& Tarragó, M. (2004). Dominación, resistencia y tecnología: la ocupación incaica en el Noroeste Argentino. Chungara, 36(2), 393-406.

Hayashida, F. M. (1999). Style, Technology, and State Production: Inka Pottery Manufacture in the Leche Valley, Peru. Latin American Antiquity, 10(4), 337-352.

Krapovickas, P. (1975). Algunos tipos cerámicos de Yavi Chico. Actas y trabajos del Primer Congreso Nacional de Arqueología Argentina (Rosario, 1970) (pp. 293-300). Museo Histórico Provincial "Dr. Julio Marc".

Krapovickas, P. (1983). Las Poblaciones indígenas históricas del sector oriental de la Puna (un intento de correlación entre la información arqueológica y la etnográfica). Relaciones de la Sociedad Argentina de Antropología, XV, 7-24.

Lehmann-Nistche, R. (1904). Catálogo de las antigüedades de la Provincia de Jujuy. Revista del Museo de La Plata, XI, 74-120.

Lemonnier, P. (1992). Elements for an Anthropology of 
Technology. Anthropological Papers, 88, 1-24.

Marchegiani, M. (2012). La variabilidad alfarera en el tambo de Punta de Balasto y la producción cerámica en Yocavil en la época de la dominación incaica (Catamarca, Noroeste Argentino). Arqueología, 18, 77-100.

Meyers, A. (1975). Algunos problemas en la clasificación del estilo Incaico. Pumapunku. Revista Oficial del Instituto de Cultura Aymara, 8, 7-25.

Nielsen, A. E. (1997). Tiempo y Cultura Material en la Quebrada de Humahuaca. 700-1650 d. C. Instituto Interdisciplinario Tilcara, FFyL, UBA.

Nielsen, A. E. (2007). El Período de Desarrollos Regionales en la Quebrada de Humahuaca: aspectos cronológicos. En V. Williams, B. Ventura, A. Callegari, \& H. Yacobaccio (Eds.), Sociedades Precolombinas Surandinas (pp. 235250). Artes Gráficas Buschi.

Nielsen, A. E, Angiorama, C. I., Maryañski, J., Ávila, F., \& López, M. L. (2015). Paisajes prehispánicos Tardíos en San Juan Mayo (frontera Argentina - Bolivia). Arqueología, 21 Dossier, 33-65.

Otero, C. (2015). Distribución y consumo de cerámica inca en el pucará de Tilcara (Quebrada de Humahuaca, Argentina). Chungara, 47(3), 401-414.

Ottonello, M. (1973). Instalación, economía y cambio cultural en el sitio Tardío de Agua Caliente de Rachaite. Publicaciones de la Dirección de Antropología e Historia, 1, 23-68.

Pérez, M., \& Killián Galván, V. (2011). Doncellas (Puna Septentrional, Jujuy, Argentina): Nuevos enfoques a partir del estudio cerámico y del análisis paleodietario. Estudios Atacameños, 42, 79-100.

Pérez de Micou, C. (1997). Indicios caravaneros en contextos funerarios de la Puna Argentina. Estudios Atacameños, 14, 143-158.

Pérez Pieroni, M. J. (2015). La manufactura cerámica prehispánica tardía y colonial en la cuenca sur de Pozuelos y el área de Santa Catalina (Jujuy, Argentina): caracterización petrográfica de pastas cerámicas. Intersecciones en Antropología, 16, 467-479.

Pérez Pieroni, M. J. (2018a). Tecnología cerámica de época colonial en la cuenca sur de Pozuelos y el área de Santa Catalina, Puna de Jujuy, Argentina. Revista de Arqueología Histórica Argentina y Latinoamericana, 12(Dossier), 116-140.

Pérez Pieroni, M. J. (2018b). Cambios y continuidades en la manufactura de materiales cerámicos del sitio Moreta (Puna de Jujuy, Argentina), s. VIII a XV AD. Estudios Sociales del NOA, 21, 145-168.

Pérez Pieroni, M. J., \& Angiorama, C. I. (2018). Evidencias arqueológicas de los siglos VII a XII AD en el asentamiento de Moreta (Puna de Jujuy, Argentina). Comechingonia, 22(1), 185-210.

Raffino, R. A., Alvis, R. J., Olivera, D. E., \& Palma, J. R. (1986). La instalación inka en la sección andina meridional de Bolivia y extremo boreal de Argentina. En R. A. Raffino (Ed.), El imperio Inka: actualización y perspectivas. Comechingonia, número especial (pp. 63-129). Instituto de Estudios Históricos.

Ruiz, M. (1996). Algunas reflexiones sobre las agrupaciones G-I-K del Pucará de Rinconada, Puna de Jujuy, República Argentina. En XXV Aniversario Museo Arqueológico Dr. Eduardo Casanova (pp. 137-144). Instituto Interdisciplinario Tilcara.

Runcio, M. A. (2012). Producción y consumo de vasijas cerámicas en la Quebrada de Humahuaca (provincia de Jujuy, Argentina) durante el período Inka (1430-1536 dC). Boletín del Museo Chileno de Arte Precolombino, 17(1), 61-73.

Suetta, J., \& Alfaro, L. (1979). Excavaciones arqueológicas en el pucará de Rinconada, Pcia. de Jujuy. Actas de las Jornadas de Arqueología del Noroeste Argentino (pp. 297-382). Universidad del Salvador.

Uribe, M., \& Agüero, C. (2005). Aproximaciones a la Puna de Atacama y la problemática Yavi. Actas del XVI Congreso Nacional de Arqueología Chilena (pp. 283291). Ediciones Escaparate.

Ventura, B. N., \& Oliveto, L. G. (2014). Resabios de otros tiempos. Dominio incaico en los valles orientales del norte de Salta, Argentina. Bulletin de l'Institut français d'études andines, 43(2), 285-310.

Vidal, A. (2019). Nadie nace sabiendo: los aprendices en la cerámica hecha a mano. Treballs d'Arqueologia, 23, 237-257. https://doi.org/10.5565/rev/tda.87

Vignati, M. A. (1938). "Novissima Veterum": Hallazgos en la Puna Jujeña. Revista del Museo de La Plata (Nueva Serie), I, 54-91.

Williams, V. I. (2000). El imperio Inka en la provincia de Catamarca. Intersecciones en Antropología, 1(1), 55-78.

Williams, V. I. (2004). Poder estatal y cultura material en el Kollasuyu. Boletín de Arqueología PUCP, 8, 209-245.

Williams, V. I., \& Cremonte, M. B. (1997). Mitmaqkuna o circulación de bienes? Indicadores de la producción cerámica como indicadores étnicos. Un caso de estudio en el Noroeste argentino. En Lorandi (Comp.), El Tucumán Colonial y Charcas (pp. 75-86). Facultad de Filosofía y Letras, Universidad Nacional de Buenos Aires.

Zaburlín, M. A. (2015). Uso, consumo y circulación de vasijas cerámicas en los pueblos prehispánicos de la laguna Guayatayoc (Puna de Jujuy). [Tesis doctoral no publicada]. Universidad Nacional de Tucumán. 